Brit. J. industr. Med., 1963, 20, 57.

\title{
A VEHICLE FOR USE AS AN AUDIOLOGY UNIT
}

\author{
BY \\ W. R. LEE, J. E. J. JOHN, and F. FOWWEATHER \\ From the Departments of Occupational Health, Audiology and Education of the Deaf, and \\ Physics (Faculty of Technology) of the University of Manchester
}

(RECEIVED FOR PUBLICATION JULY 2, 1962)

Reliable measurement of hearing by audiometry requires quiet surroundings for which suggested criteria exist. When field studies of hearing are carried out it is frequently most practicable to use a vehicle in which these desired sound levels are obtained. It was decided to incorporate in the design of this vehicle a consulting room and a waiting room so that the patient could adjust to the surroundings for what is essentially a psychological test. Ventilation is effected by input and extractor fans.

As a basis for the acoustic design the sound levels in typical situations where the van was to be used were determined. From these it is possible to estimate the attenuation required. The walls and roof of the vehicle are of solid construction with a surface density of $5 \mathrm{lb}$./sq. $\mathrm{ft}$., and the floor has a surface density of $6 \mathrm{lb}$./sq. $\mathrm{ft}$. A commercially made booth is suspended on resilient mountings inside the consulting room. The total weight of all the equipment and the sound proofing is in the region of 2 to 3 tons.

After construction the sound attenuation of the vehicle was measured in nearly uniform sound fields, provided by a power station and jet engines. Measurements were made simultaneously outside the vehicle, in the consulting room, and inside the booth. The readings were taken in $1 / 3$ octave bands with a calibrated condenser microphone and audio-frequency spectrometer. The results show that the attenuation of the vehicle shell closely follows the predicted value for $5 \mathrm{lb}$./sq. $\mathrm{ft}$. Subtraction of the overall attenuation from the octave band sound levels in typical factory yards gave a measure of the sound levels to be expected within the booth under field conditions. These showed that the vehicle should be suitable for audiometric measurements of frequencies above 100 cycles per second. To get an accurate value of the attenuation of the booth, which is not symmetrically placed in the consulting room, a source giving a uniform field in the horizontal plane was placed inside the booth and sound level measurements made there and in the consulting room.

Deafness due to high intensity noise at work is attracting more and more interest both in the spheres of industrial health and audiology. Field studies of industrial deafness are complicated by many factors, one of which is the difficulty of finding a room that is sufficiently quiet to permit of valid and reliable measurements of hearing. In many industries airborne and structure-borne noise is often transmitted throughout the factory at very high levels and even in administrative and social areas, the noise levels, although perhaps lower than the working areas, may be too high for audiometric purposes. The erection of a properly designed audiology unit in the vicinity could be impossible or impracticable for a variety of reasons, and it may be impracticable to transport workers to an audiology clinic. In planning field studies of industrial deafness it has been found necessary to construct vehicles in which satisfactory acoustic conditions could be obtained to serve as mobile audiology clinics. A description of one such vehicle has been given by Pennington (1958) while Dickson and Wheeler (1953), Royal Canadian Air Force (1946) and Sullivan and Hodges (1952) have described vehicles for audiometry on air-fields. The latter two vehicles were designed for use close to very high intensity noise sources, whereas in industrial surveys it is usually possible to put the vehicle on relatively quiet sites, thus taking advantage of the baffle effect of walls, administrative blocks, or stores, which would provide some protection from the noise generated by machinery. The vehicle described in this article was designed primarily for investigations of deafness in the cotton industry. 


\section{Design}

Investigations of hearing and of the possible causes of defects of hearing involve careful history taking, otological examination, and both speech and pure tone audiometry. The design of audiology clinics, whether mobile or static, must take into account the fact that measurements of hearing are essentially psychological. We do not examine hearing directly but note the response of a subject to sound. We generate sounds of various kinds at different loudness levels and record which of them evoke responses. The reliability of these tests, as of all psychological tests, is in part a function of the atmosphere in which they are conducted; this must not only not generate feelings of apprehension and anxiety in the subjects but should also tend to relieve any such feelings that subjects may have had before coming to the clinic.

Consideration of these points led to the decision that although space was severely restricted a waiting room should be included in the vehicle. Although the rooms were made as large as possible they were still small and, therefore, it was necessary to provide very good artificial lighting and ventilation. It was also decided that in order to provide a subject with further opportunity to adjust himself to the situation his history should be taken in the vehicle before the otological and audiometric examinations.

Consulting Room.-Wherever clinical examinations are carried out it is necessary to have a supply of water for washing hands and sterilizing instruments. The possibilities of a gravity feed water tank in the roof or a tank under the floor with a pumped supply were considered, but because of the likelihood of sound being carried into the van along the water pipes, it was decided to mount the fresh and waste water tanks inside the sound-proofing. Arrangements could then be made for filling and emptying the tanks when the van was not otherwise in use.

A fold-down couch was fitted into the consulting room, for general medical examinations or for caloric stimulation testing, if necessary.

Ventilation.-The need to avoid continuous air paths along which noise can be transmitted always gives rise to problems of ventilation. Properly designed ducts can be used in buildings to provide ventilation while retaining satisfactory noise control but such ducts would for a variety of reasons have been quite impracticable on a vehicle of reasonable size. It was decided to install a system that would effect a complete change of air at frequent convenient intervals. Extractor fans at one end of the vehicle body and input at the other enable the air to be changed rapidly between examinations. The fans are situated in ventilators covered by tightly fitting flaps which act as sound locks and close only under positive pressure. In closing, the flaps operate microgap switches to stop the fans. The complete exclusion of sound is, of course, only necessary during the audiometric tests, and the flaps can be opened to allow some movement of air during the other parts of the examination.

In industrial audiometry it is frequently desirable for the tests to be carried out before work starts. A complete rapid air change in the vehicle at 6 a.m. or 7 a.m. in the winter's morning of a North country mill town would involve a sudden marked fall in air temperature which, for the comfort of the operator and subjects, would have to be made good rapidly. It was found by trials in a mock-up room of the size of the proposed consulting room that this could be done effectively with 2 and 3 kilowatt fan heaters.

Electrical Supplies.-To avoid the subjective impression of being closed in a small space, a high level of illumination, 600 watts, has been provided in the consulting room and 200 watts in the waiting room. These, together with the requirements for the fan heaters, ventilating fans, instrument sterilizer, and water heater (for hand washing) gave an estimated possible peak load of about $40 \mathrm{amp}$. and a running load that could be 20 to $30 \mathrm{amp}$.

Several factors influence the siting of a vehicle such as this during field surveys and one of these is the availability of adequate electrical supplies. Once the expected current load exceeds $15 \mathrm{amp}$. special connexions have to be arranged. In order that positions of electrical connexions should not unduly limit the choice of site for the vehicle, it was decided to carry 150 feet of cable. Flexible cable to supply the loadings described above was selected and bore a $50 \mathrm{amp}$. rating. This provided an adequate safety factor for overloading and reduced the cable voltage drop to a minimum. Nevertheless, measurements at factories have shown a 7 volt drop in the cable at full load and a variation in mains supply voltage of up to 14 volts. A disadvantage of this cable is its weight and physical size which make handling inconvenient.

Another problem that might arise from the use of a long lead connected to the electrical earth system of the factory is that leakage currents of several millivolts might be encountered. These would prove disturbing when connected to the screened leads used for audiometry. For this reason provision was made for the independent earthing of the audiometric screened leads by means of an earth spike and for the ordinary audiometer earth to be disconnected when this spike is in use in order to avoid an "earth loop". 


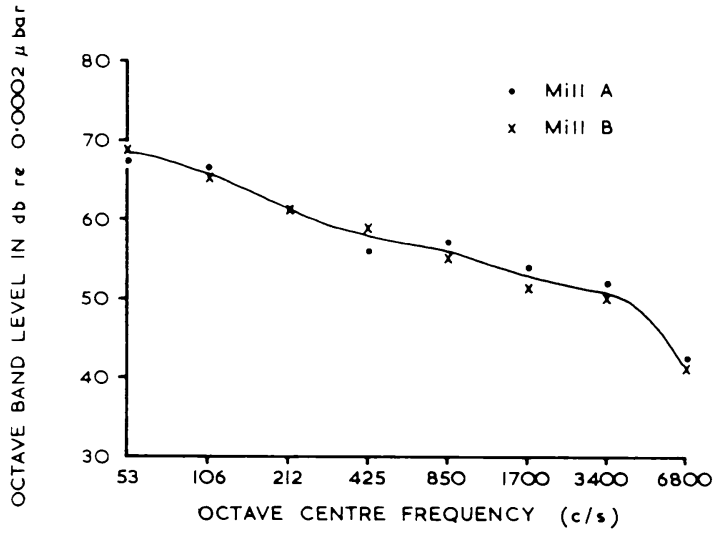

Fic. 1.- Octave band analyses of noise levels in typical mill yards.

Acoustic Design.-As the vehicle was designed for audiometric surveys on workers in the textile industry, the insulation had to be sufficient to attenuate sound levels in a mill yard to those specified for audiometric testing (Webster, 1954; Cox, 1955; Glorig and Harris, 1957). Octave band analyses of noise in a mill yard were taken (Fig. 1). These figures gave a measure of the problem to be faced.

In view of the engineering difficulties of making the whole bodywork of the vehicle as two chambers, one suspended inside another by resilient mounts, it was decided to use a commercially made booth with a specified noise attenuation. This was mounted in the vehicle on flexible rubber mountings and the vehicle body so designed that, together with the booth, the required attenuation would be achieved.

A section of the walls of the vehicle is shown in Fig. 2. The wall is supported on a $1.5 \mathrm{in}$. hardwood

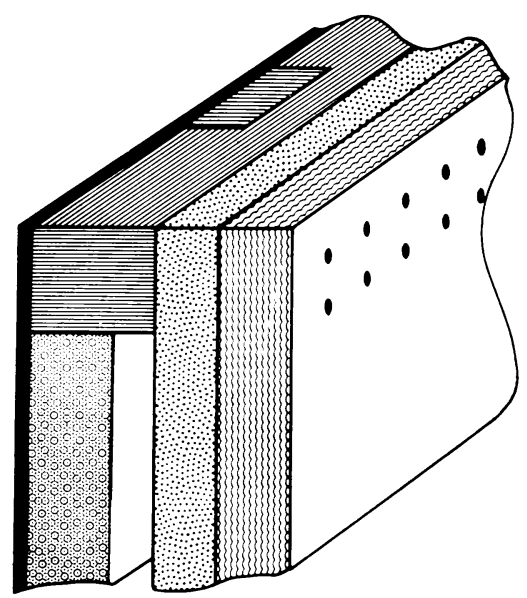

Fig. 2.-Cross-section of wall. frame, the outer skin being the glass fibre sheet. Glass fibre was chosen for the bodywork to withstand prolonged exposure to the atmosphere of a Northern industrial town and because of its known resistance to impact damage. Sheets of "weyroc" (density $42 \mathrm{lb}$. $\mathrm{cu}$. ft.) were attached to the inner side of the framework; the joins in the weyroc were overlapped 3 in. and sealed with "bostik". In the 1.5 in. deep cells of the framework a 1 in. layer of fibre glass (density $12 \mathrm{lb} . / \mathrm{cu}$. ft.) was fixed to the glass fibre body. The innermost layer of the wall is of $\frac{13}{16} \mathrm{in}$. "acoustic celotex C3" tile fixed to the weyroc by adhesives. This last layer provides the necessary control of reverberation for speech audiometry. The ceiling was constructed in a similar way and the surface density of walls and ceiling was about $5 \mathrm{lb}$./sq. ft. The floor was made of 1 in. timber boards, tongued and grooved, tightly packed, and sealed. The boards were covered with overlapped and sealed weyroc sheets cemented to the floor boards, and over this, for strength, was attached a layer of hardboard. The walking surface of the floor is made of a rubber composition, "bulgomme silence". The surface density of the floor is about $6 \mathrm{lb}$./sq. ft. (Fig. 3).

\section{Chassis Requirements}

Size.-From the plan view (Fig. 4) it will be seen that the waiting room is about $7 \times 4 \mathrm{ft}$. and the clinical examination room $7 \times 8 \mathrm{ft}$. The $7 \mathrm{ft}$. measurement corresponds with the width of the vehicle, allowing for an additional 3 in. either side for the sound insulation, the maximum legal overall width being $7 \mathrm{ft} .6 \mathrm{in}$. The overall length of the body is about $13-14 \mathrm{ft}$. The booth is about $7 \mathrm{ft} .9 \mathrm{in}$. high and the body stands about $8 \mathrm{ft}$. above its floor level. To carry a body of this size a chassis in the range of 1.5 to 5 tons is required.

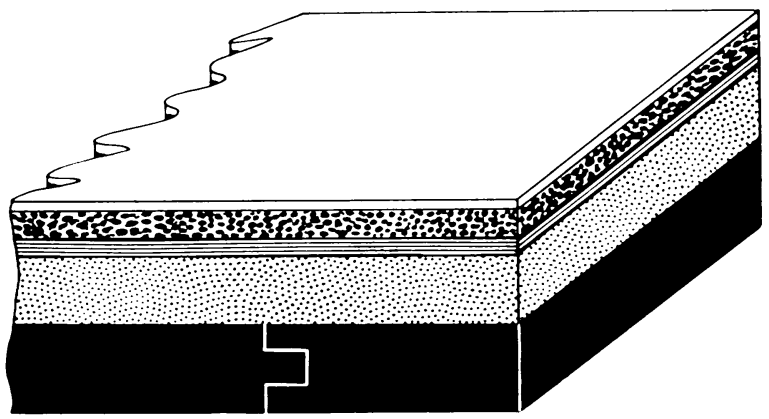

FIG. 3.-Cross-section of floor. 


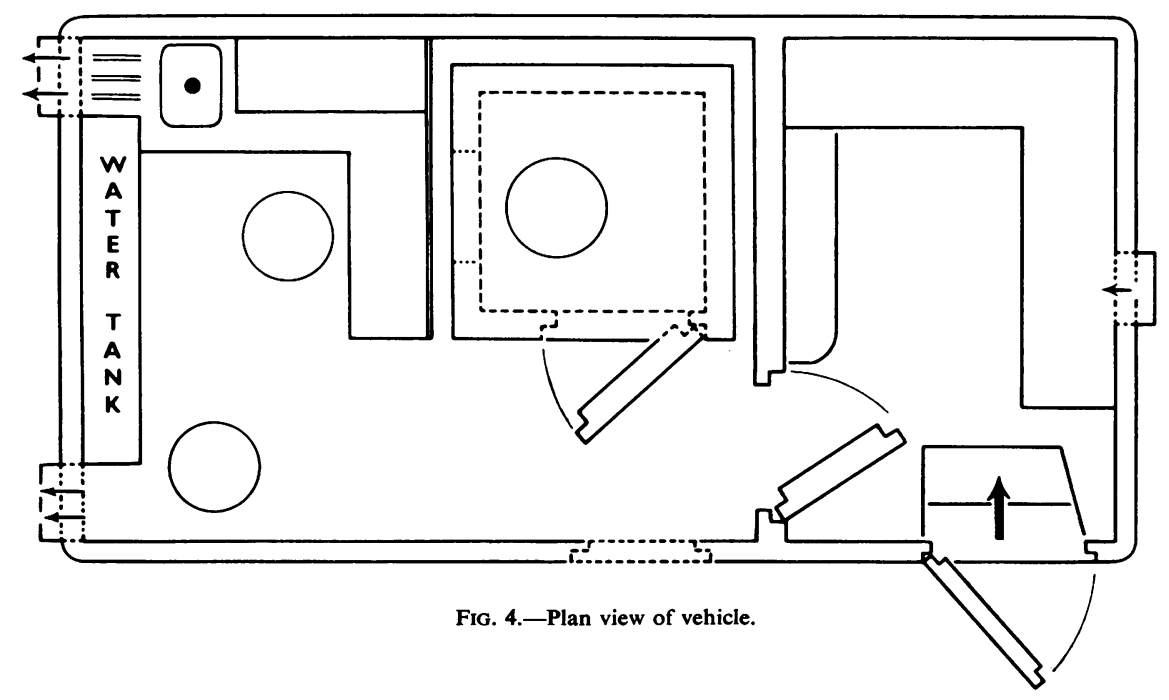

Weight.-The weight of the sound damped bodywork was estimated at $17 \mathrm{cwt}$. and the acoustic booth at $12 \frac{1}{2} \mathrm{cwt}$. To this was added the weight of equipment carried, including a full water tank, bringing the total weight into the region of 2-3 tons.

Make.-Field surveys require that the maximum number of subjects in a selected sample are seen (ideally, this would be the whole sample). Anything that might discourage people from attending must be eliminated; a suitable chassis was necessary therefore so that elderly persons would not have to climb many or high steps to the floor level of the vehicle.

Furthermore, it was not expected that the van would travel many miles during use, although it is hoped that its life will be several years, and for these reasons a petrol-engined version of a recently introduced chassis was selected. These considerations, with the advice of an independent engineer, led to the selection of a Bedford 3-ton TK Chassis/Cab.

\section{Van Attenuation Measurements}

The measurement of the effectiveness of any sound-attenuating device requires that sound level measurements be made on the source side and on the receiving side with the device in a uniform sound field, the difference between the two readings being the attenuation, or transmission loss, of the device for the particular frequency or frequency band for measurements with a noise source.

A power station was used as a noise source for the first measurements, and an almost uniform field of overall level $96.5 \pm 1.5 \mathrm{db}$ was obtained with the van in the reverberant field of the generating hall. The measurements were made in $1 / 3$ rd octave bands using a Bruel and Kjaer condenser microphone and audio-frequency spectrometer, the calibration of which was checked by a piston-phone as standard noise source. Measurements were made at six microphone positions outside the van, two positions in the consulting room, and one position both in the booth and waiting room. Average values of sound level were used to obtain the overall attenuation of the van (i.e. outside to inside the booth), and also the attenuation of the van shell (i.e. outside to inside the consulting room). These results are plotted as dots in Fig. 5. (van shell attenuation) and in Fig. 6 (overall attenuation). It will be seen that measurements were only made up to $1 / 3$ rd octave centre frequency of $3,150 \mathrm{c} / \mathrm{s}$ for the van shell and $400 \mathrm{c} / \mathrm{s}$ for the overall attenuation, because the power station noise falls off at the higher frequencies; hence a noise source with a higher output at high frequencies was required to extend the range of measurement.

The second set of measurements was made with jet engines as noise source. The van was placed about 30 yards from the nose of the aeroplane, and the measurements were made during the testing of the engines. The van was in a sound field of $116 \pm$ $2.5 \mathrm{db}$, which was only constant for the order of minutes and necessitated a changed technique of measurement. Two microphones and amplifiers were now used, and by means of a rotating mechanical switch six seconds of each output were recorded in turn on magnetic tape. The piston-phone was used to calibrate the gain of each amplifying system, and also to record a standard signal of $124 \mathrm{db}$ on the 


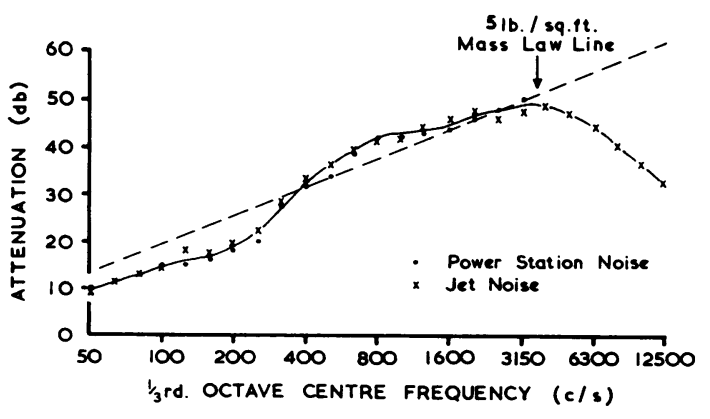

FIG. 5.-Sound attenuation of van shell (outside to consulting room) compared with $5 \mathrm{lb}$./sq. ft. incidence law.

tape. Recordings were made with the microphones in the same positions as at the power station. The $1 / 3$ rd octave band analysis was made using several tape loops cut from consecutive six-second recordings, the gain of the play-back system being adjusted by the tape loop of the standard source; average values were used to calculate attenuation. The results are plotted as crosses in Fig. 5 and Fig. 6. The measurements in both cases are now extended to $12,500 \mathrm{c} / \mathrm{s}$; the low frequency values are in good agreement with the earlier results.

The van shell has a surface density of $5 \mathrm{lb}$./sq. $\mathrm{ft}$. and the floor $6 \mathrm{lb}$./sq. $\mathrm{ft}$., hence it is possible to draw on Fig. 5 the theoretical mass law straight line attenuation for $5 \mathrm{lb}$./sq. $\mathrm{ft}$.; this line is shown dotted and is in good agreement with the measured values.

It is not possible to obtain an accurate value of the attenuation of the audiometric booth by subtraction of Fig. 5 from Fig. 6, since the booth is not symmetrically placed in the consulting room and therefore will not be in a uniform sound field. The attenuation of the booth was measured, using a source giving a uniform field in the horizontal plane and placed inside the booth (Fig. 7); this consisted of a modified column loudspeaker fed from a tape loop of jet engine noise. Measurements were made in the booth and at two positions in the consulting room; the attenuation is shown in Fig. 8 at $1 / 3$ rd octave intervals.

The workable frequency range for audiometric measurements was obtained by subtracting the overall attenuation from the octave band sound levels (Fig. 1) in mill yards and comparing the result with Harris's modification of the Webster and Cox data for the minimum acceptable octave-band noise levels for audiometric rooms (Glorig and Harris, 1957). These two curves are plotted in Fig. 9, and show that the van is satisfactory for audiometric measurements of frequencies above $100 \mathrm{c} / \mathrm{s}$. Fig. 10 is a photograph of the finished vehicle.

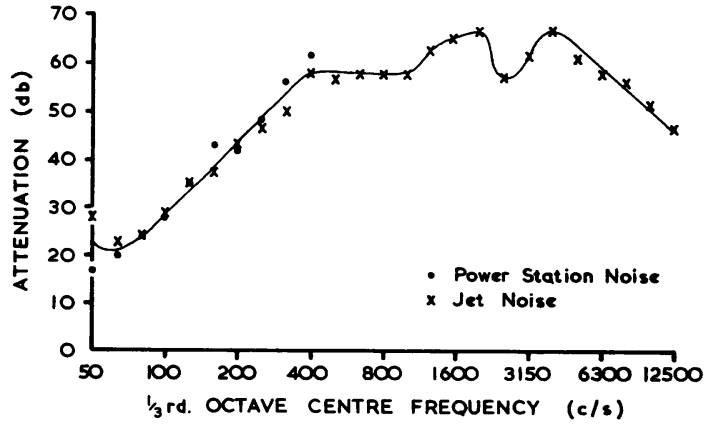

FIG. 6.-Overall sound attenuation (outside to booth).

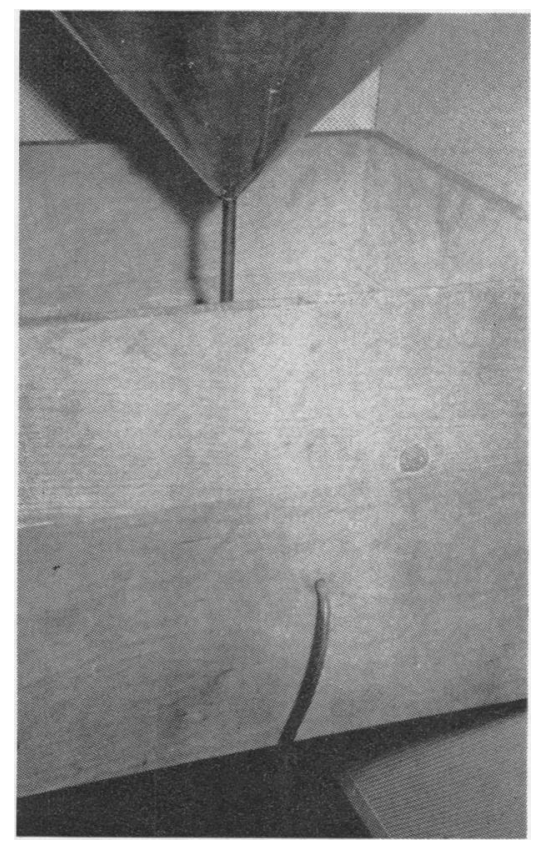

Fig. 7.-Apparatus for measurement of sound attenuation of booth.

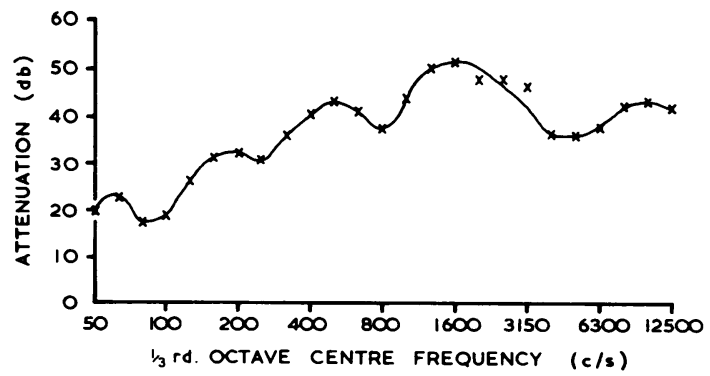

FIG. 8.-Sound attenuation of booth (booth to consulting room). 


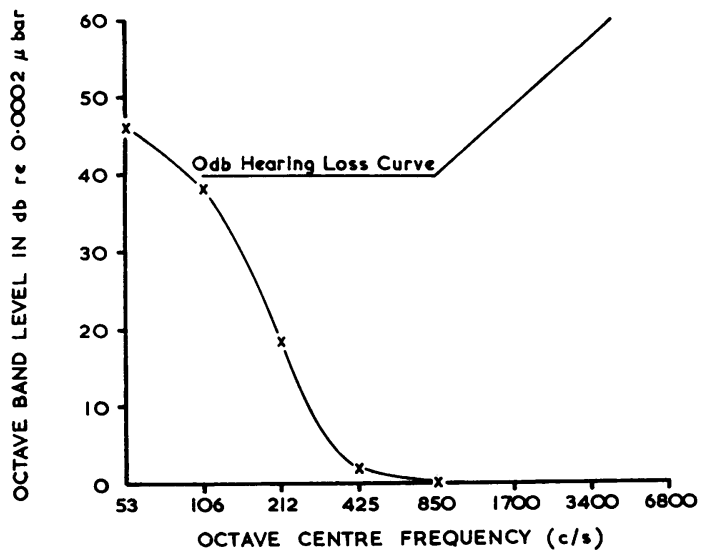

FIG. 9.-Predicted noise level in booth, with vehicle in mill yard, compared with minimum acceptable octave-band-noise levels (after Webster and Cox).

The construction of this vehicle was made possible by a generous gift from the British Cotton Growing Association. The measurements were made with acoustic measuring equipment obtained on a grant to one of us (F.F.) from the Department of Scientific and Industrial Research.

We would like to thank Professor R. E. Lane of the Nuffield Department of Occupational Health for his continued encouragement and support, together with Professor Sir Alexander Ewing of the Department of Audiology and Education of the Deaf, and Professor V. F. Lambert and Mr. D. L. Chadwick, lecturer in the Department of Otolaryngology, for their help in the design.

Acknowledgment is made also to Dr. A. J. King of A.E.I. (Metropolitan Vickers Ltd.), Dr. T. S. Littler of the Medical Research Council, and to the National Physical Laboratory for advice on acoustic design.

Col. W. H. Slack readily gave valuable advice at all stages from initial planning to completion, and we are greatly indebted to him. Messrs. C. H. Frazer and R. Ryding of the former Samlesbury Engineering Ltd. contributed by their interest and technical knowledge of construction. Commander K. N. Hoare, M.B.E. of Manchester City Fire Brigade advised on fire precautions and Messrs. A. C. Critch and G. S. Jackson of the North Western Electricity Board advised on electrical problems.

We are grateful to the Regional Director, Central Electricity Generating Board for permission to take measurements in a Power Station and similarly to the management and to Dr. G. Taylor and Mr. P. Brown of A. V. Roe Ltd., for their permission and assistance with measurements in the sound field of jet aircraft.

\section{REFERENCES}

Cox, J. R., Jr. (1955). Noise Control, 1, 25

Dickson, E. D. D., and Wheeler, L. J. (1953). Nature (Lond.), 172. 748.

Glorig, A., and Harris, J. D. (1957). In Handbook of Noise Control, ed. C. M. Harris, Chap. 6, p. 6. McGraw-Hill, London.

Pennington, G. F. (1958). Ann. occup. Hyg., 1, 128.

Royal Canadian Air Force (1946). J. Canad. med. Serv., 4, 22.

Sullivan, J. A., and Hodges, W. E. (1952). J. Aviat. Med., 23, 229.

Webster, J. C. (1954). J. acoust. Soc. Amer., 26, 782.

\section{ADDENDUM}

The Webster and Cox data used as a reference for acceptability of audiometric rooms refer to the American standard of Normal Threshold. If a correction is employed for the equivalent British standard the upper curve of Fig. 9 is altered, but the van remains satisfactory for audiometric measurements of frequencies of 125 cycles per second and above.

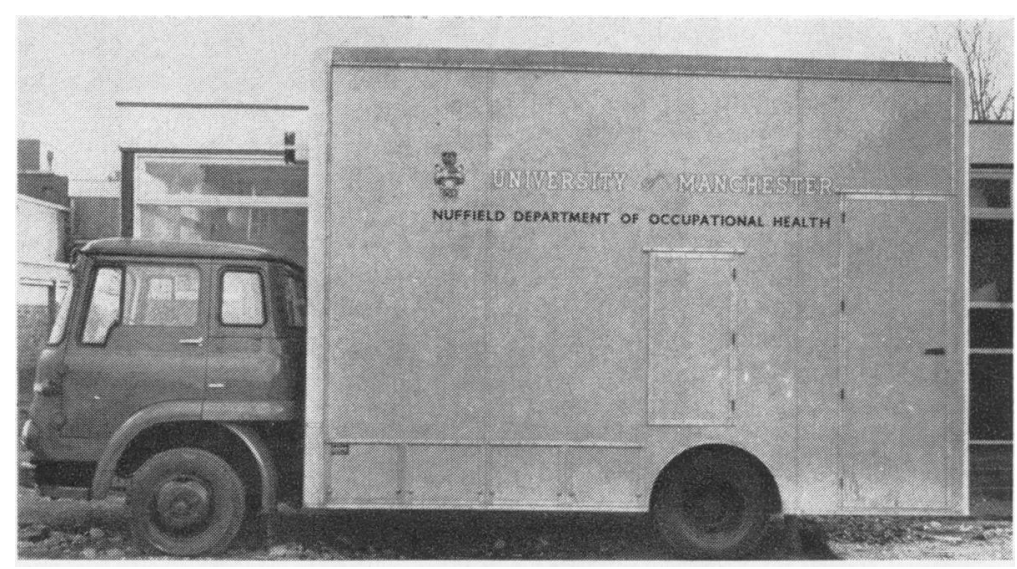

Fig. 10.-Photograph of finished vehicle. 